\title{
Interlay myringoplasty: hearing gain and outcomein large central tympanic membrane perforation
}

\author{
Subramanya BT ${ }^{1}$, Lohith $S^{2}$, Sphoorthi $B^{3}$ \\ ${ }^{1}$ Subramanya BT., Associate Professor, Department of ENT at Subbaiah Institute of Medical Sciences, Shivamogga, \\ Karnataka, India. ${ }^{2}$ Dr. Lohith S., Assistant Professor, Department of ENT at Subbaiah Institute of Medical Sciences, \\ Shivamogga, Karnataka, India. ${ }^{3}$ Sphoorthi B., Assistant Professor, Department of ENT at Subbaiah Institute of Medical \\ Sciences, Shivamogga, Karnataka, India.
}

Corresponding Author: Dr. Lohith S., Assistant Professor, Department of ENT at Subbaiah Institute of Medical Sciences, Shivamogga, Karnataka, India, Email: dr.shivappalohith@gmail.com

\begin{abstract}
Background: Tympanic membrane Perforations primarily results from middle ear infections and myringoplasty is a surgical procedure used to repair the tympanic membrane and to improve hearing. The interlay technique is a newer safe and technique that has shown higher success rates and is considered better than both overlay as well as the underlay techniques. Aims and objectives: To analyze the results of interlay myringoplasty, in terms of graft uptake and hearing improvement in cases of chronic suppurative otitis media with inactive mucosal disease with large central perforation. Materials and Methods: This is a prospective study conducted from August 2015 to January 2018 in 60 patients of chronic suppurative otitis media (CSOM) with large central perforation. All patients underwent interlay myringoplasty through post aural approach after clinical examination, audiometric tests \& routine investigations. Patients were called for regular follow up for 12 weeks. Results: The graft uptake rate in the present study was found to be $93.33 \%$, Pre operatively mean air bone gap was $28.5 \pm 6.96 \mathrm{~dB}$ and Post operatively after 12 weeks mean air bone gap improved to 15.83 \pm 3.37 . Conclusion: Interlay myringoplasty with a superiorly based TM flap is an effective technique over conventional methods in terms of both graft uptake as well as hearing improvement in large central perforation.
\end{abstract}

Key words: Inactive mucosal chronic otitis media, interlay, tympanoplasty, air bone gap, graft uptake.

\section{Introduction}

Perforation of the tympanic membrane primarily results from middle ear infections, howeverit can also result from various forms of trauma including iatrogenic injuries, thermal injuries and pressure effects. Up to $80 \%$ of these perforations have the tendency of spontaneous healing [1]. Myringoplasty is a surgical procedure used to repair the tympanic membrane and to improve hearing level where the ossicular chain is intact and mobile [2].

Myringoplasty confers considerable benefits that include prevention of recurrent discharge, improvement in hearing, protection against long-term middle ear damage by preventing the ossicular pathology and prevention of migration of squamous epithelium around the margins of perforation with possible consequence of cholesteatoma formation [3]. Three most universally

Manuscript received: $20^{\text {th }}$ July 2018

Reviewed: $30^{\text {th }}$ July 2018

Author Corrected: $7^{\text {th }}$ August 2018

Accepted for Publication: $12^{\text {th }}$ August 2018 accepted techniques for graft positioning are overlay, underlay and interlay, with each one of these having its own advantages and disadvantages [4]. Although each technique is improvised version of the other technique yet the choice of technique is mostly dependent on the surgeon's familiarity with the particular procedure. In such a scenario, it is difficult to claim the relative superiority of a single technique. Temporalis fascia is the most commonly used graft material.

The interlay technique (graft supported by the mucosal layer medially and the fibrous and squamous layer laterally)is a newer technique thathas shown promising results with success rates higher than 90\% [5] [6].

Interlay technique is considered better than both overlay as well as the underlay techniques as getting an interlay plane is easier and faster, there is no reduction in the middle ear space, the bed size for the graft is not limited, faster healing time andno fear of residual 
epithelium and epithelial pearl formation. There are lesschances of graft medialization or lateralization, blunting of the anterior meatal recess and there is no fear of residual epithelium [7].

\section{Aims and objectives}

To analyze the results of interlay myringoplasty, in terms of graft uptake and hearing improvement in cases of chronic suppurative otitis media with inactive mucosal disease with large central perforation.

\section{Materials and Methods}

Place of study- The present study was conducted at Subbaiah institute of medical sciences, Shimoga from August 2015 to January 2018.

Type of study- This is a randomised descriptive longitudinal study conducted after clearance from the Ethical Committee. Patients were properly informed regarding the nature of the disease process, proposed surgical procedure including expected outcomes, potential complications and alternative treatments. Written consent was obtained from patient and attendant both.

Inclusion criteria- Patients with inactive mucosal chronic otitis media [COM] having large central perforation in which the ear had been dry for at least 6 weeks

Exclusion criteria- Patients with active mucosal COM, active or inactive squamosal COM, ossicular discontinuity, tympanosclerosis, revision surgeries, sensorineural /mixed hearing loss, presence of focus of infection in nose, sinuses, or throat, and failure to followup for at least 3 months. All these cases had undergone detailed workup which included history, thorough clinical examination of ear, nose, and throat including examination under microscope, tuning fork tests, pure tone audiometry, X-ray mastoid (Shuller's view) and routine lab investigations.

All the cases were performed under local anesthesia with sedation, through post auricular approach, using true temporal is fascia graft. In all these cases, after freshening of margins, a superiorly based tympanomeatal flap was elevated circumferentially along with the annulus, leaving behind the mucosal layer of remnant tympanic membrane.

Canaloplasty was done wherever required. Fresh temporalis fascia was then harvested and grafted over the remnant mucosal layer, under the maleus handle and on the bony canal walls all around after placing the adequate gel foam in the middle ear.

The tympanomeatal flap was then reposited and gel foam was placed again in the external auditory canal. The patient was followed up on a regular basis, at $1^{\text {st }}$ 2nd week, 4th week, 8th week, and 12th week. At 12th week, a postoperative pure tone audiogram was done to assess and compare the hearing levels. The criterion for success was restoration of an intact tympanicmembrane and improvement $\mathrm{ABG}$ of at least $10 \mathrm{~dB}$.

Stastical methods- Paired t test was used to statistically analyse the results.

\section{Results}

The present study comprised of total 60 patients of which $34(56.66 \%)$ were male and $26(43.33 \%)$ were female patients. The age of the patients ranged from 16 to 60 years, with the mean agebeing 36.48 years with standard deviation 12.61 and maximum number of patients were in the age group of 31 to 40 years.

Table-1: Age distribution of the patients.

\begin{tabular}{|c|c|c|}
\hline Age group (years) & Number of patients & $\boldsymbol{\%}$ \\
\hline $11-20$ & 8 & 13.33 \\
\hline $21-30$ & 14 & 23.33 \\
\hline $31-40$ & 16 & 26.66 \\
\hline $41-50$ & 12 & 20 \\
\hline $51-60$ & 10 & 16.66 \\
\hline Total & $\mathbf{6 0}$ & $\mathbf{1 0 0}$ \\
\hline
\end{tabular}


Table-2: Gender distribution of the patients.

\begin{tabular}{|c|c|c|}
\hline Gender & Number & $\%$ \\
\hline Male & 34 & 56.66 \\
\hline Female & 26 & 43.33 \\
\hline Total & $\mathbf{6 0}$ & $\mathbf{1 0 0}$ \\
\hline
\end{tabular}

The preoperative air-bone gap (ABG) was between 11 and $20 \mathrm{~dB}$ in 12(20\%) patients, 21-30 dB in 33(55\%) patients and $31-40 \mathrm{~dB}$ in $15(25 \%)$ patients, with the mean ABG being $28.5 \mathrm{~dB}$ with standard deviation of 6.96 as shown in table 3.

Table-3: Preoperative airbone gap of the patients.

\begin{tabular}{|c|c|c|}
\hline Pre operative ABG(dB) & Number of patients & \% \\
\hline$<10$ & 0 & 20 \\
\hline $11-20$ & 12 & 55 \\
\hline $21-30$ & 33 & 25 \\
\hline $31-40$ & 15 & 0 \\
\hline
\end{tabular}

Post operatively graft accepted in 56(93.33\%) patients while graftrejection was observed in 4(6.66\%) patients at the end of 12 weeks as shown in table 4.

Table-4: Outcome of graft uptake at 12 week follow up.

\begin{tabular}{|c|c|c|}
\hline Graft outcome & Number of patients & $\%$ \\
\hline Accepted & 56 & 93.33 \\
\hline Rejected & 4 & 6.66 \\
\hline
\end{tabular}

At the end of 12 weeks the post operative mean $\mathrm{ABG}$ was reduced to $15.83 \mathrm{~dB}$ with standard deviation 3.37 and the postoperative $\mathrm{ABG}$ changing to less than $10 \mathrm{~dB}$ in 10(16.66) patients, between 11 and $20 \mathrm{~dB}$ in 39(65\%) patients and between 21 and $30 \mathrm{~dB}$ in 11(18.33\%) patients, all of which were statistically significant.

Table-5: Postoperative air bone gap of the patients.

\begin{tabular}{|c|c|c|}
\hline Post operative ABG(dB) & Number of patients & $\%$ \\
\hline$<10$ & 10 & 16.66 \\
\hline $11-20$ & 39 & 18.33 \\
\hline $21-30$ & 0 & 0 \\
\hline $31-40$ & 11 & 05 \\
\hline
\end{tabular}

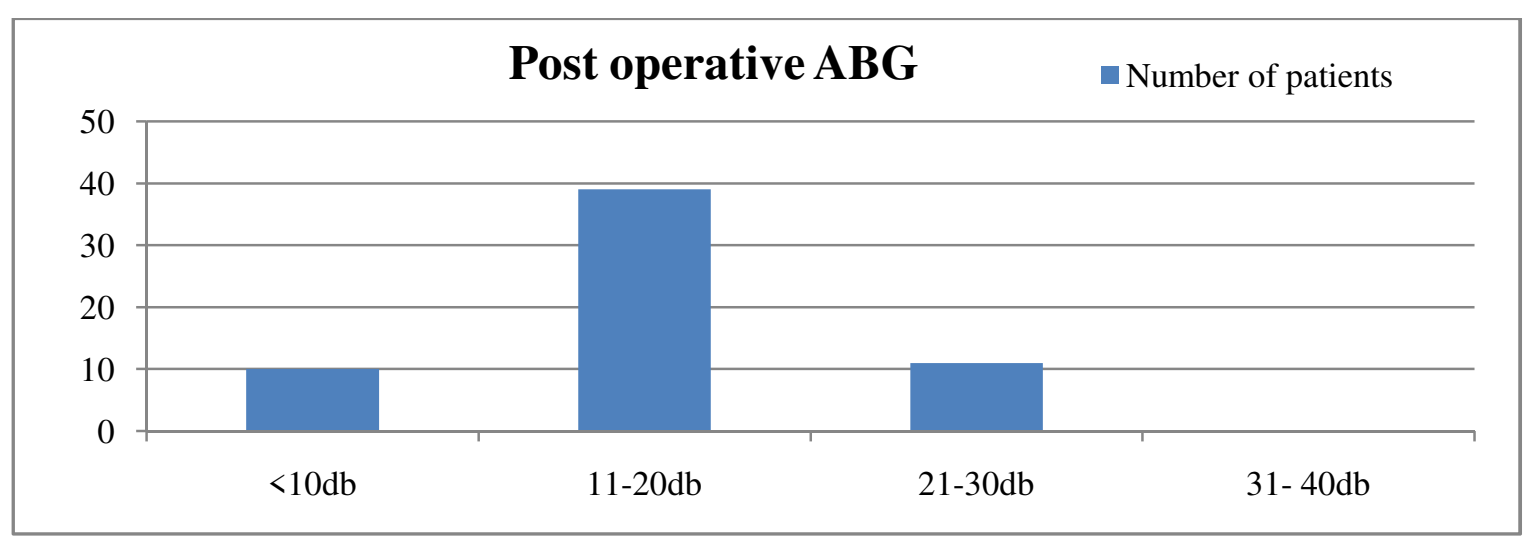

Figure-1 


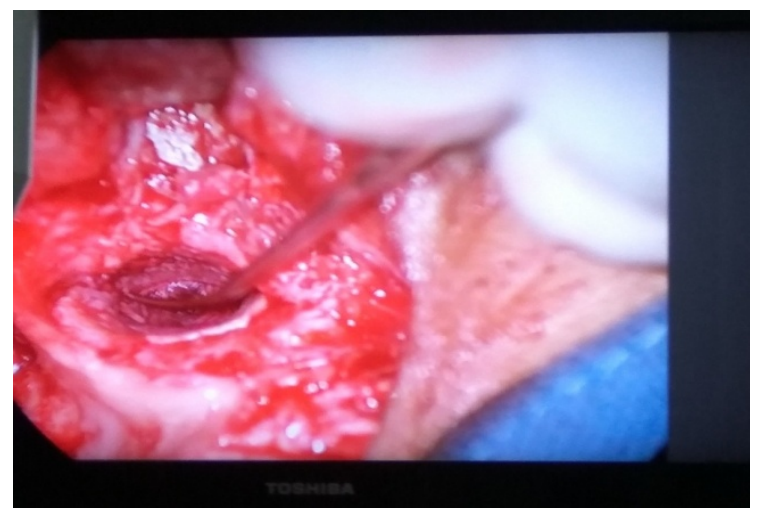

Fig 2: Intra operative image of left ear showing graft in place medial to handle of maleus between fibrosquamous and mucosal layers

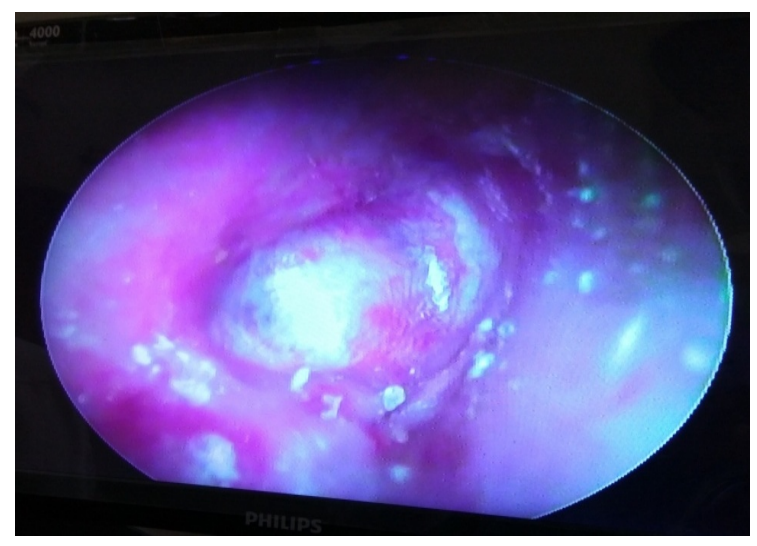

Fig 4: Post operative image at the end of 12 weeks Showing well taken up graft no anterior blunting or epithelial pearl formation

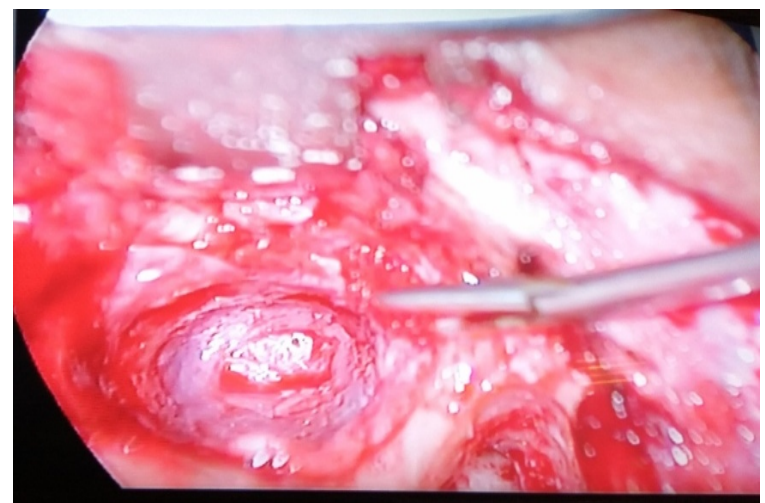

Fig 3: Intra operative image of right ear showing graft in place medial to handle of maleus between fibrosquamous and mucosal layers

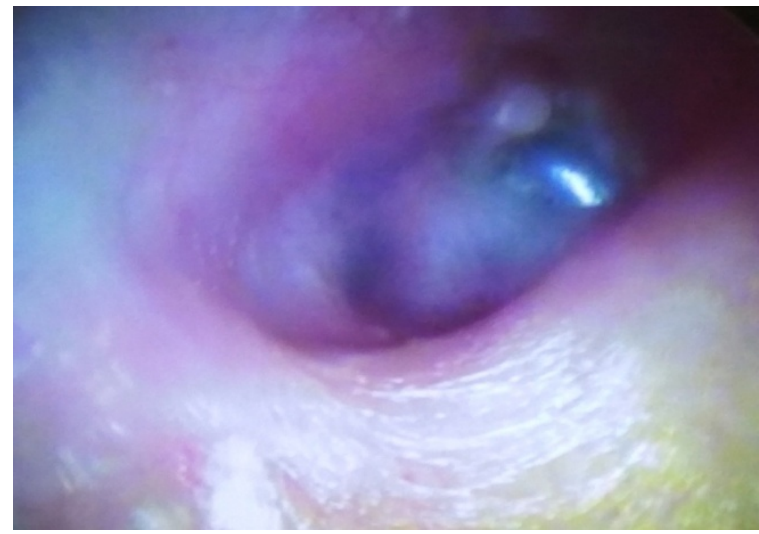

Fig 5: Post operative image at the end of 12 weeks showing well taken up graft no anterior blunting or epithelial pearl formation.

\section{Discussion}

Chronic suppurative otitis media (CSOM) is the inflammation confined to the mucoperiosteal lining of the middle ear cleft. It is the result of an initial episode of acute otitis media and is characterized by a persistent discharge from the middleear through a tympanic membrane perforation. It is an important cause of preventable hearing loss, particularly in the developing world. Myringoplasty is the simplest operative procedure performed to repair the perforation in ear drum by repairing the tympanicmembrane only. It is performed in cases with central perforation and intact ossicular chainand is a beneficial procedure to protect the middle ear and inner ear from future deterioration and also provides improvement in hearing after surgery [8] [9]. Several factors may affect surgical outcome such as the surgical approach (endaural, postaural), site of perforation, type of graft utilized and technique used. There are many techniques to perform this procedure such as Underlay, Overlay, Inlay, Gel film Sandwich, Swinging Door, Triple C, Double breasting, Antero superior anchoring and LASER assisted spot welding.

Underlay and the overlay arethe two classical techniques that are commonly performed. Underlay is widely used and relatively simple to perform where the graft is placed medial to the remaining drum under the mucosal layer of tympanic membrane. This technique is ideal to repair small and medium sized perforations. Anterior canal blunting and lateralization of the graft are less, the drum heals at the correct level relative to the annulus and it is quick and easy to perform. On the other hand, its disadvantages are that the middle ear space is reduced and adhesions may occur, there is increased failure because of a limited bed size for the graft with poor vascularity and it is not the ideal technique for perforations extending into the anterior annulus since placement of the graft is difficult. In contrast, the overlay technique is more challenging and typically reserved for total perforations, anterior perforations, or failed underlay surgery. In the overlay technique, the graft is placed lateral to the annulus, there is an excellent visualization of the anterior meatal 
recess, which is important in cases of anterior perforations reaching the anterior annulus. In addition, the healing rate is high because the drum is essentially replaced intact and the middle ear space is not reduced. The most serious disadvantages are longer healing time, blunting of the anterior meatal recess, the lateralization of the graft, epithelial pearl formation and the iatrogenic cholesteatoma.

In the last few years, a newer technique Interlay is gaining popularity and being successfully used with promising results. In interlay procedure, the graft is sandwiched between the canal wall and the remnant drum mucosa on one side and tympanomeatal flap with squamous and fibrous layers on the other side. Thus, a sufficiently large raw area is available to serve as the vascular bed providing adequate blood supply to the graft. Hence the average time of epithelization of graft is much shorter than other techniques, healing rate is superior and gain in hearing is more in comparison to other techniques [6] [10].

The superiorly based flap gives the advantage of wide exposure and allows good anchoring of the graft all aroundthe bony annulus. If required, canalplasty can be easily performed due to circumferential elevation of the tympanomeatal flap without causing tear in the flap thus further giving a wider exposure and helping in easy placement of the graft. Canal plasty was done in 10 cases in our study where anterior bony canal overhang was obscuring the visualization of the annulus. The chance of anterior canal wall blunting is not seen in interlay technique as the fibrous annulus which is elevated during the procedure is placed back onto the bony annulus all around. There is no medialisation or lateralisation of the graft as the graft is supported medially by the mucosal layer and laterally by the fibro-squamous layer. As the mucosal layer is below the graft there are no chances of endothelium overgrowing on the graft leading to myringitis. The fibro-squamous layer of the tympanic membrane is elevated completely hence there is no fear of leaving residual epithelium behind leading to the formation of epithelial pearls or an iatrogenic cholesteatoma.

In the present study, the graft uptake rate was found to be $93.33 \%$ which is in accordance with study by Kawatraet al [2]. Who reported success rate of $93.3 \%$ and is slightly better than study conducted by Hay et al [11]. On 116 ears who found success rate of $91 \%$.

Jain S et al [4] studied 500 cases and reported the success rate of 96.6 and Patil et al [7] reported $96 \%$ which is slightly better than our results. Komune S et al [6] studied interlay myringoplasty in 69 ears and achieved success rate of $94.2 \%$, either blunting of the anterior tympanomeatal angle nor lateralization of the tympanic membrane was observed in any of their cases.

Interlay technique reportedly has a high success rate. A comparative account of success rate for interlay technique as reported in various studies is shown in Table 6.

Table-6: Success rate for Interlay Technique as reported in different case series.

\begin{tabular}{|c|c|c|c|c|}
\hline Sl.No & Author & Year & Number of cases & Success (\%) \\
\hline 1 & Komune S et al [6] & 1992 & 69 & 94 \\
\hline 2 & Hay et al [11] & 2014 & 116 & 91 \\
\hline 3 & Jain S et al [4] & 2017 & 500 & 96.6 \\
\hline 4 & Kawatraet al [2] & 2014 & 30 & 93.3 \\
\hline 5 & Patil et al [7] & 2014 & 100 & 96 \\
\hline 6 & Present study & 2018 & 60 & 93.33 \\
\hline
\end{tabular}

In the present study $\mathrm{ABG}$ changed from $28.5 \mathrm{~dB}$ preoperatively to $15.83 \mathrm{~dB}$ post operatively at the end of 12 weeks. In study by Jain $\mathrm{S}$ et al [4] the mean ABG was $26.08 \pm 8.32 \mathrm{~dB}$ and the hearing improved in 477 (95.4\%) patients with the mean postoperative $\mathrm{ABG}$ reducing to $10.12 \pm 5.84 \mathrm{~dB}$.

In the study by Kawatraet al [2] ABG improved from $27.50 \mathrm{~dB}$ preoperatively to $13.67 \mathrm{~dB}$ postoperatively after 16 weeks and in study by Patil et al [7] the mean preoperative ABG was $36.42 \pm 12.01 \mathrm{~dB}$ which improved to $9.7 \pm 6.71 \mathrm{~dB}$ at the end of 3rd month. 


\section{Conclusion}

Although Interlay myringoplasty technique requires additional expertise in surgery, it is an effective technique over conventional methods like overlay or underlay for graft uptake and hearing gain (audiological improvement) in large central perforation. The superiorly based circumferential TM flap provides wide exposure to allow good anchoring of the graft all around the bonyannulus and avoids graft medialisation, lateralization, anterior canal blunting, risk of epithelial pearl formation or Cholesteatoma formation. The findings in present study substantiate the results obtained in some recent studies. Thus Interlay myringoplasty with a superiorly based TM flapshould be preferred over the other conventional techniques in patients with chronic suppurative otitis media (CSOM) inactive mucosal disease with large central perforation.

Funding: Nil, Conflict of interest: Nil

Permission from IRB: Yes

\section{References}

1. Galdstone HB, Jackler RK, Varav K. Tympanic Membrane Wound Healing. An Overview.Otolaryngol Clin North Am. 1995 Oct;28(5):913-32.

2. Kawatra R, Maheshwari P, Kumar G. A comparative study of the techniques of myringoplasty - Overlay, underlay \& interlay.IOSR J Dent Med Sci.2014;13:12-6

3. Bluestone CD, Cantekin EI, Douglas GS.Eustachian tube function related to the results of tympanoplasty in children. Laryngoscope. 1979 Mar; 89 (3):450-8.doi:10. 1288/ 00005537-197903000-00013.

4. Jain S, Gupta N, Gupta R, Roy A. Interlay Type I tympanoplasty in large central perforations: Analysis of 500 cases. Indian J Otol 2017;23:32-5.
5. Guo M, Huang Y, Wang J. Report of myringoplasty with interlay method in 53 ears perforation of tympani. Lin Chuang Er Bi Yan Hou Ke Za Zhi. 1999 Apr;13 (4): 147-9.

6. Komune S, Wakizono S, Hisashi $\mathrm{K}$, Uemura $\mathrm{T}$. Interlay method for myringoplasty. Auris Nasus Larynx. 1992;19(1):17-22.

7. Patil BC, Misale PR, Mane RS, Mohite AA. Outcome of interlaygrafting in type 1 tympanoplasty for large central perforation. Indian JOtolaryngol Head Neck Surg. 2014;66:418 24.doi:10.1007/s12070-0140741-3.

8. Wullstein H, Theory And Practice Of Myringoplasty. Laryngoscope. 1956 Aug; 66 (8):1076-93.doi:10.1288/ 00005537-195608000-00008.

9. Hussain A, Yousaf N, Khan AR. Outcome of myringoplasty. Jrnl of PG Med Inst Peshawar 2004;18 (4):695-8.

10. Singh M, Rai A, Bandyopadhyay S, Gupta SC. Comparative study of the underlay andoverlay techniques of myringoplasty in large and subtotal perforations of the tympanicmembrane. J Laryngol Otol. 2003 Jun;117(6):444-8.doi:10.1258/0022215033 21892262

11. Hay A, Blanshard J. The anterior interlay myringoplasty: Outcome and hearing results in anterior and subtotal tympanic membrane perforations. Otol Neurotol. 2014 Oct;35(9):1569-76. DOI:10.1097/MAO. 0000000000000503

\section{How to cite this article?}

Subramanya BT, Lohith S, Sphoorthi B. Interlay myringoplasty: hearing gain and outcomein large central tympanic membrane perforation. Trop J Ophthalmol Otolaryngol.2018;3(3):39-44.doi:10.17511/jooo.2018.i03.06 